\title{
Patterns of recovery of airflow obstruction in severe acute asthma
}

\author{
IAN S. Petheram \\ M.B., M.R.C.P.*
}

\author{
D. A. JONES \\ M.B., M.R.C.P.
}

\author{
J. V. Collins \\ M.D., M.R.C.P. \\ Brompton Hospital, Fulham Road, London SW3 $6 H P$
}

\begin{abstract}
Summary
The speed and patterns of recovery of airflow obstruction were analysed in 209 patients receiving a standard therapeutic regime for severe acute asthma. Initial rates of recovery were rapid. Three-quarters of the patients had achieved $50 \%$ of their total improvement in peak expiratory flow rate (PEFR) within $24 \mathrm{hr}$. The time taken to reach eventual maximum PEFR was very much longer, $50 \%$ of the patients taking one week or more. Diurnal variation of moderate or severe degree was seen in $78 \%$ of patients. Length of history of asthma, time of deterioration and other measures of the severity of attack on admission did not differ in faster and slower responders. The rise of PEFR within $4 \mathrm{hr}$ of starting treatment was highly significantly correlated with a higher PEFR at $24 \mathrm{hr}$ and a shorter time to full recovery. Although the mean arterial $\mathrm{PCO}_{2}$ was higher $(P<0.01)$ in the slower responding group and they were slightly older $(P<0.05)$ and had lower mean FEV $1 \quad(P<0.02)$ and FVC $(P<0.05)$ these differences were less helpful in predicting which patients responded fastest.
\end{abstract}

\section{Introduction}

Frequent measurement of airflow obstruction is necessary for the correct management of asthma both in the long term and during treatment of the severe acute attack (Turner-Warwick, 1977; Seaton, 1978). Although decreases in heart rates and pulsus paradoxus have been shown to reflect recovery from severe asthma (Rees, Miller and Donald, 1968; Knowles and Clark, 1973) there have been few observations on the speed and patterns of response of airflow obstruction during recovery. The authors examined the speed and patterns of response of airflow obstruction by recording 4-hourly peak expiratory flow rate (PEFR) measurement in patients

\footnotetext{
*Present address: University College Hospital, Gower Street, London WC1.
}

receiving a standard regime of treatment. In patients responding more slowly than expected an attempt was made to identify factors that might have predicted this.

\section{Subjects and methods}

Patients admitted with severe exacerbations of asthma unresponsive to routine maintenance therapy and who required intensive treatment in a special unit were studied during a 2-year period (1976-1977). Excluded patients were those with chronic bronchitis, emphysema, bronchiectasis or bronchopulmonary aspergillosis. All patients were managed in a uniform way. Following initial inhaled salbutamol given by nebuliser or intermittent positive pressure breathing, an intravenous infusion containing aminophylline $500 \mathrm{mg}$ 8-hourly and hydrocortisone $200 \mathrm{mg}$ 6-hourly was given with oral prednisolone $40-60 \mathrm{mg} /$ day in divided doses. Oxygen, antibiotics and physiotherapy were given when indicated. For each patient studied the duration of history of asthma, the length of the present exacerbation and the pattern of asthma in the previous year were noted. The severity of the exacerbation was assessed by physical examination, arterial blood gas analysis and measures of airflow obstruction.

Response of airflow obstruction measured by PEFR was assessed as follows:

(i) Initial response to therapy was assessed by the change in PEFR $4 \mathrm{hr}$ after starting treatment. This was expressed as a percentage of PEFR obtained on admission.

(ii) The time taken to achieve maximum improvement in PEFR and the time taken to achieve half that eventual improvement.

(iii) The incidence and severity of diurnal variation (morning fall in PEFR expressed as a percentage of highest value of previous day) was noted.

(iv) In an attempt to identify factors that might 


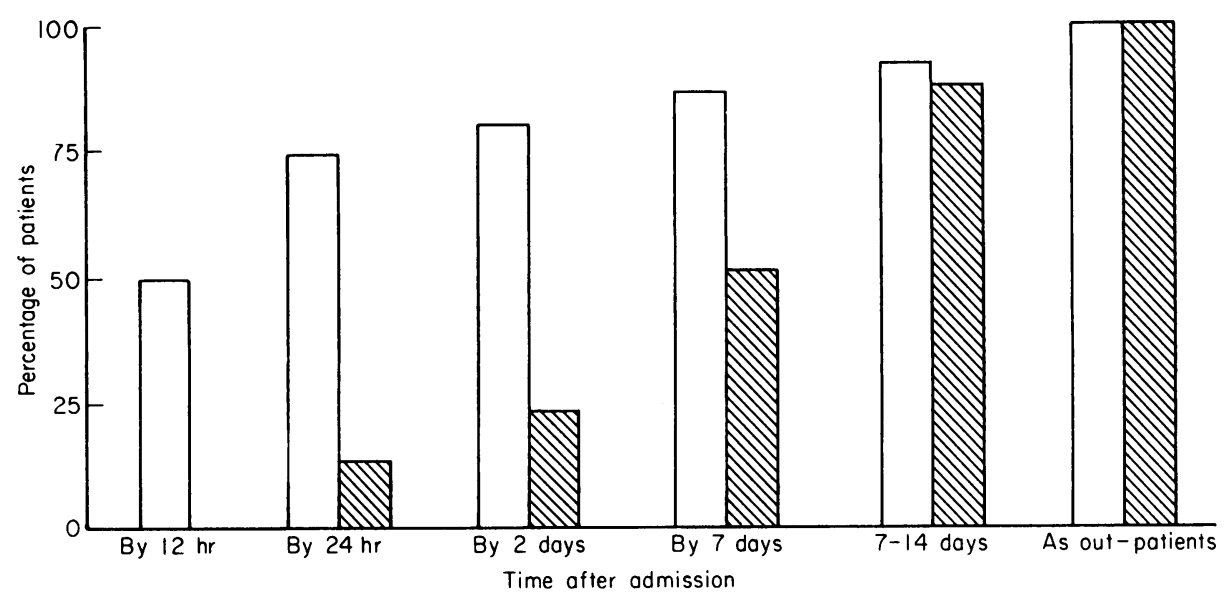

Fig. 1. Percentage of patients who achieved half their maximum improvement $\square$ and maximum improvement at the times shown after admission.

predict which patients would respond more quickly than others, those who had achieved half their total eventual improvement of PEFR by $24 \mathrm{hr}$ (faster responders, Group 1) were compared with those who had taken $24 \mathrm{hr}$ to reach this degree of recovery (slower responders, Group 2). Differences in the length of history of asthma and periods of deterioration between the 2 groups were tested statistically by $\chi^{2}$ tests and differences in mean values were compared by $t$ tests.

\section{Results}

\section{Initial response to treatment}

In $47(23 \%)$ patients, PEFR had improved by at least $100 \% 4 \mathrm{hr}$ after admission and in 122 patients $(58 \%)$ it had improved by at least $50 \%$. Only 26 $(12 \%)$ had not improved at all. Appropriate recordings were not available in 5 patients. In 4 patients PEFR had fallen following an initial satisfactory response.

\section{Time taken to total and half total improvement}

The percentage of patients who had achieved maximum improvement and half maximum improvement at the times shown after admission is shown in Fig. 1. Although $98(47 \%)$ patients had achieved half their eventual improvement by $12 \mathrm{hr}$ and 145 patients $(69 \%)$ by $24 \mathrm{hr}$, only $25(12 \%)$ had reached maximum improvement after 24 hr's treatment. After treatment for one week, only $107(51 \%)$ patients had reached their maximum PEFR and after 2 weeks $15 \%$ had still not reached maximum. Some patients continued to improve to their maximum PEFR even after discharge from hospital.

\section{Diurnal variation}

This was very common. Severe variation (greater than $50 \%$ fall) occurred in $39 \%$ patients and mod- $\mathcal{}$ erate variation $(25-50 \%$ fall) in another $39 \%$. Sixteen 은 per cent. of patients had mild variation (less than $\overrightarrow{ }$ $25 \%$ fall) and only $6 \%$ showed no variation at all. Diurnal variation started most commonly between the third and fifth day of treatment.

\section{Comparison of faster with slower responders}

One hundred and forty-five patients had reach half their eventual improvement within $24 \mathrm{hr}$ of admission (faster responders, Group 1) and 64 took longer (slower responders, Group 2). For each group the mean ages, sex incidence, incidence of atopy and $\stackrel{2}{\circ}$ previous treatment with maintenance oral cortico- $\unrhd$ steroids are shown in Table 1. Group mean values for $\overrightarrow{\overrightarrow{0}}$ heart rate, pulsus paradoxus, arterial blood gas $\exists$ analysis and measures of airflow obstruction, all $\vec{F}$ measured on admission, are shown in Table 2. The mean age of patients in the faster responding group was slightly lower than that of the slower 3 . responders $(P<0.05)$ and they also had a slightly lower mean arterial $\mathrm{PCO}_{2}(\boldsymbol{P}<\mathbf{0} \cdot \mathbf{0 1})$ and higher mean FEV $_{1}(P<0.02)$ and FVC $(P<0.05)$. There was no significant difference in the total length of history of asthma, number of exacerbations in the 음 previous year and duration of the present exacer- $\rightarrow$ bation between the 2 groups. There was no evidence that pre-admission treatment with intravenous $N$ aminophylline or other bronchodilator drugs in- 5 fluenced the speed of recovery. The achievement of $\tilde{O}$ half maximum improvement of PEFR by $24 \mathrm{hr}$ was $\underset{\mathrm{\omega}}{\mathrm{\omega}}$ highly significantly correlated with both the response 0 by $4 \mathrm{hr}(P<0.001)$ and time taken to total improve- 0 ment $(P<0.001)$. Sixty-two per cent. of patients in $\overparen{D}$ Group 1 had improved their admission PEFR reading $\stackrel{?}{?}$ by at least $50 \%$ (Table 3) and $67 \%$ had achieved 
TABLE 1. Mean age ( \pm one s.d.) sex ratio, incidence of atopy and consumption of oral corticosteroids in 2 groups of patients

\begin{tabular}{|c|c|c|c|c|c|}
\hline Groups & No. & $\begin{array}{c}\text { Mean age } \\
\text { (years) }\end{array}$ & $\mathbf{M}$ & $\mathbf{F}$ & $\begin{array}{c}\text { Atopic Maintenance } \\
\text { oral steroids } \\
\text { (Percentage) }\end{array}$ \\
\hline 1. Faster responders & 145 & $\begin{array}{l}41(15.3) \\
P<0.05\end{array}$ & 41 & 104 & 43 \\
\hline 2. Slower responders & 64 & $46(16 \cdot 3)$ & 23 & 41 & 50 \\
\hline
\end{tabular}

TABLE 2. Mean values ( \pm one s.d.) obtained in 2 groups of patients on admission

\begin{tabular}{|c|c|c|c|c|c|c|c|c|}
\hline Groups & $\begin{array}{l}\text { Mean heart } \\
\text { rate } \\
\text { (per min) }\end{array}$ & $\begin{array}{l}\text { Mean paradox } \\
(\mathrm{mmHg})\end{array}$ & $\underset{(\mathrm{kPa})}{\mathrm{Mean} \mathrm{PO}_{2}}$ & $\begin{array}{l}\text { Mean } P \mathrm{CO}_{2} \\
\quad(\mathrm{kPa})\end{array}$ & $\mathrm{pH}$ & $\begin{array}{l}\text { PEFR } \\
(1 / \mathrm{min})\end{array}$ & FEV $_{1}$ (litre) & FVC (litre) \\
\hline $\begin{array}{l}\text { 1. Faster } \\
\text { responders }\end{array}$ & $105 \cdot 1(19 \cdot 96)$ & $16 \cdot 8(13 \cdot 3)$ & $8.4(1.85)$ & $\begin{array}{l}4.71(0.91) \\
P<0.01\end{array}$ & $7.4(0.065)$ & $107(40 \cdot 5)$ & $\begin{array}{l}0.7(0.32) \\
P<0.02\end{array}$ & $\begin{array}{c}1.39(0.62) \\
P<0.05\end{array}$ \\
\hline $\begin{array}{l}\text { 2. Slower } \\
\text { responders }\end{array}$ & $104 \cdot 1(16.87)$ & $16 \cdot 2(12 \cdot 1)$ & $8.0(1.52)$ & $5.2(0.69)$ & $7.39(0.075)$ & $104(38 \cdot 2)$ & $0.57(0.24)$ & $1.16(0.47)$ \\
\hline
\end{tabular}

maximum improvement within one week of admission (Table 4) whereas $69 \%$ of Group 2 failed to improve their admission PEFR by as much as $50 \%$ (Table 3) and three quarters took longer than one week to reach maximum PEFR (Table 4).

TABle 3. Percentage improvement over admission PFR by $4 \mathrm{hr}$

\begin{tabular}{llcc}
\hline \multicolumn{1}{c}{ Group } & $<50 \%$ & $>50 \%$ \\
\hline 1. & Faster responders & 38 & 62 \\
2. & Slower responders & 69 & 31 \\
\hline
\end{tabular}

Percentage of cases $P<0.001\left(\chi^{2}\right)$

TABLe 4. Time to maximum PFR (days)

\begin{tabular}{lllll}
\hline Groups & $<7$ days & $7-14$ days & $>14$ days \\
\hline 1. & Faster responders & 67 & 22 & 11 \\
2. & Slower responders & 25 & 51 & 24 \\
\hline
\end{tabular}

Percentage of cases $P<0.001\left(\chi^{2}\right)$

\section{Discussion}

This study showed that in most patients with severe exacerbations of asthma airflow obstruction responded rapidly to the regime of treatment used at this hospital. Half the patients had achieved at least $50 \%$ of their eventual maximum PEFR within $12 \mathrm{hr}$ of the start of treatment and three quarters had reached this point of their recovery by $24 \mathrm{hr}$. A rapid clinical response to treatment in severe asthma has been noted previously. Rebuck and Read (1971) found clinical improvement usually began within minutes or hours in their study of 76 admissions for severe asthma. In their series, however, relapse occurred on 17 occasions but reasons for this were not analysed. Similarly when Kelsen et al. (1978) treated 127 exacerbations in an emergency outpatient room using a regime that did not include corticosteroids they were able to send $85 \%$ of the patients home but a quarter of these had further equally severe episodes of asthma within 10 days. Of the 209 admissions in the present study, relapse following initial improvement in PFR occurred on only 4 occasions. Significant effects of cortiscosteroids on airways obstruction are not seen for about $6 \mathrm{hr}$ even when administered intravenously (Collins et al., 1975; McFadden et al., 1976). The low relapse rate in the present study suggests that corticosteroids may prevent worsening of airflow obstruction following the initial improvement achieved by nonsteroid bronchodilators by enhancing the response of asthmatic patients to adrenergic drugs (Andersson, Bergh and Svedmyr, 1972).

Despite the initial rapid response shown within hours of starting treatment, the time taken for most patients to achieve maximum was very much longer. By $24 \mathrm{hr}$ after admission only $12 \%$ had reached their maximum PEFR and after treatment for one week only $50 \%$ had achieved their maximum. Symptoms and physical signs resolve early during recovery (Rebuck and Read, 1971) but hypoxaemia may persist long after clinical recovery. This study shows that some patients may still have a degree of airways obstruction even after discharge from hospital. Patients who relapse have less improvement in FEV following initial treatment (Rebuck and Read, 1971; Kelsen et al., 1978). Regular measurement of airflow obstruction using a peak flow meter might help identify patients likely to deteriorate particularly if corticosteroids have been withheld. 
In this study diurnal variation in airflow obstruction was very common, occurring in more than $75 \%$ of patients during recovery. There was a greater incidence of diurnal variation in faster compared with slower responders and the variation tended to be more severe in the former. Hetzel, Clark and Branthwaite (1977) found the risk of sudden death correlated with excessive diurnal variation but not with the severity of asthmatic attack. Severe variation started about the fourth day of treatment and could continue for days or weeks. The cause of diurnal variation is unknown and its long-term management presents many problems (Turner-Warwick, 1977). The identification of mechanisms responsible and effective treatment are urgently needed if the incidence of sudden death in asthma is to be reduced.

The identification of patients who will have a rapid and sustained improvement in contrast to those who will require more prolonged treatment, or those likely to relapse, would be of great clinical value. Although the faster responding group were slightly younger, had lower arterial $\mathrm{PCO}_{2}$ tensions and higher FEV $_{1}$ and FVC, the differences were of low significance and do not provide a reliable guide to the speed of recovery. The most useful information for predicting which patients will reach their maximum PEFR soonest was the improvement in peak flow rate obtained $4 \mathrm{hr}$ after starting treatment. There was no evidence that the length of history of asthma, number of exacerbations in the previous year or the period of deterioration of the attacks studied affected the speed of response. There was no indication that those who took longest to recover were more severly hypoxic, had faster heart rates or more pulsus paradoxus but they had statistically significant lower mean FEV $_{1}$ and FVC on admission. These readings, however, were less well correlated with the speed of response. The reasons why some patients took longer to recover than others are unclear. There was no evidence that upper or lower respiratory bacterial infection assessed clinically influenced the rate of recovery. Viral infection causing exacerbations of asthma may be responsible for the slow response to therapy. Airways obstruction measured by serial PEFR recordings took significantly longer to recover during a recent in-patient epidemic of proved influenza infection causing exacerbations in 5 asthmatics previously in remission (Jones et al., 1978).
Measurement of airway obstruction is now accep- $\frac{2}{3}$ ted as essential for assessing severe acute asthma. The $\stackrel{\varnothing}{\varnothing}$ authors suggest that 4-hourly PEFR recordings are $c$. valuable in assessing the adequacy of initial response to treatment, in identifying patients who need longer $\stackrel{5}{+}$ than average treatment and in revealing excessive $\bar{c}$ diurnal variation which renders the patient at risk $\frac{\bar{\sigma}}{\bar{\rho}}$ from sudden death when the exacerbation of asthma has apparently resolved.

\section{Acknowledgments}

We thank the physicians at Brompton Hospital for allow- $\vec{\omega}$ ing us access to patients under their care and Ms Terry Chudleigh for preparing the tables and manuscript.

\section{References}

ANDERSSON, R., Bergh, N.P. \& SVEDMYR, N. (1972) Metabolic actions in human bronchial muscle associated with ACTH-induced relaxation. Scandinavian Journal of $\mathrm{O}$
Respiratory Diseases, 53, 215.

Collins, J.V., Clark, T.J.H., Brown, D. \& Townsend, J. (1975) The use of cortiscosteroids in the treatment of $\square$ acute asthma. Quarterly Journal of Medicine, 44, 259.

Hetuel, M.R., Clark, T.J.H. \& Branthwaite, M.A. (1977)尺 Asthma: analysis of sudden deaths and ventilatory arrests in hospital. British Medical Journal, 1, 808.

Jones, D.A., Petheram, I.S., Collins, J.V. \& Taylor, $\mathscr{O}$. (1978) Effect of influenza A2 virus infection on pulmonady $\vec{v}$ function in adults with asthma. Proceedings of X Congress of Internal Medicine (in press).

Kelsen, S.G., Kelsen, D.P., Fleegler, B.F., Jones, R.C.亭 RoDMAN, J. (1978) Emergency room assessment and treatment of patients with acute asthma. American Journal of Medicine, 64, 622.

Knowles, G.K. \& ClaRK, T.J.H. (1973) Pulsus paradoxus as a valuable sign indicating severity of asthma. Lancet, ii, $\stackrel{\varnothing}{\varnothing}$ 1356

McFadden, E.R., Kiser, R., De Groot, W.J., Holmes, B., $\overrightarrow{\bar{\sigma}}$ KIKER, R. \& VISER, G. (1976) A controlled study of the effects of single doses of hydrocortisone on the resolution? of acute attacks of asthma. American Journal of Medicine, $60,52$.

ReBUCK, A.S. \& READ, J. (1971) Assessment and management $\frac{\partial}{3}$ of severe asthma. American Journal of Medicine, 51, 788.

ReES, H.A., Miller, J.S. \& DonAlD, K.W. (1968) A study of the clinical course and arterial blood gas tensions of patients in status asthmaticus. Quarterly Journal of Medicine, 37, 541.

SEATON, A. (1978) The management of recurrent severe asthma. In: Advanced Medicine (Ed. by Weatherall, D.J.)윽 14th Edn, pp. 350-357. Pitman Medical, London.

TURNER-WARWICK, M. (1977) On observing patterns of airflow obstruction in chronic asthma. British Journal of Diseases of the Chest, 71, 73. 